\title{
Violencia basada en género: un problema de Salud Pública
}

La violencia contra las mujeres es una atrocidad de dimensiones mundiales. En todo el mundo, la vida de las mujeres se ve afectada por experiencias o amenazas de violencia sin distinción de posición económica, raza o cultura. En el hogar y en la comunidad, en la guerra y en tiempo de paz, a las mujeres se les golpea, se les viola, se les mutila y se les mata impunemente.

En algún momento de sus vidas más de la mitad de las mujeres latinoamericanas ha sido objeto de agresiones en sus hogares. Un 33\% fue víctima de abusos sexuales entre las edades de 16 y 49 años, mientras un $45 \%$ recibió amenazas e insultos y sufrió la destrucción de objetos personales.

La violencia ejercida dentro del recinto familiar ha merecido especial preocupación tanto por las organizaciones de mujeres, como por investigadores, organismos de gobierno y agencias de desarrollo. Y es que este tipo de violencia afecta no solo a las mujeres, sino al entorno familiar, especialmente a los niños. Otro aspecto igualmente poco destacado, es el que se refiere a la relación entre dependencia económica y violencia física. Un estudio del Banco Interamericano de Desarrollo encontró que el $41 \%$ de las mujeres no asalariadas son golpeadas por sus maridos o convivientes, frente al $10 \%$ de las que tienen trabajo remunerado. Ciertamente, lo que está en juego son las relaciones asimétricas de poder entre mujeres y hombres que determinan en última instancia, la posición de subordinación y vulnerabilidad de las mujeres, independientemente de su situación socioeconómica.

La violencia basada en género aparece como una causa significativa de discapacidad y muerte entre mujeres con edad reproductiva.

Las mujeres blanco de la violencia pueden padecer de estrés crónico y, por consecuencia, de enfermedades tales como la hipertensión, diabetes, asma y obesidad; frecuentemente, como consecuencia del abuso tanto físico como psicológico, las mujeres sufren dolores de cabeza en forma crónica, trastornos sexuales, depresiones, fobias y miedos prolongados.

Ahora bien, esta violencia no solo causa daños irreparables en los sobrevivientes, sino que puede terminar en muchos casos con la muerte. La muerte de mujeres a manos de sus esposos, amantes, padres, novios, pretendientes, conocidos o desconocidos, no solo es el producto de casos no explicados de conducta desviada o patología: estas muertes son femicidios, la forma más extrema de violencia de género.

Solo durante 2005, en nuestro país se produjeron 39 femicidios. La Universidad de Costa Rica, en el marco del Centro de Investigaciones en Estudios de la Mujer, coordinó la realización de la Primera Encuesta Nacional de Violencia de Genero, en la cual se evidenció que el 57.7\% de las entrevistadas habían sufrido al menos un incidente de violencia física o sexual en algún momento de sus vidas. Una cuarta parte reportó haber tenido 4 ó más incidentes de violencia física o sexual desde los 16 años.

Reconocer los avances de esta lucha y valorar medios y posibilidades para reforzarlos, por un lado, y por el otro, dar una mirada crítica a las dificultades e identificar oportunidades para avanzar más y mejor en la erradicación de la violencia contra la mujer, constituyen las ideasfuerza que dan sentido a las acciones que se pueden tomar al respecto. Al igual que los médicos son entrenados para detectar signos y síntomas del "síndrome de niño agredido"; se les debe capacitar para el reconocimiento temprano de la mujer agredida y para tomar las medidas 
Ante este fenómeno de la violencia contra la mujer y de conformidad con los enfoques de equidad de género, de derechos humanos y acorde con la conciencia del valor que tiene el aprendizaje social con otras personas y organizaciones, el Ministerio de Salud dio a conocer este año la Política de Igualdad de Género elaborada por la Organización Panamericana de la Salud, y el documento Fortaleciendo la respuesta del Sector Salud a la violencia basada en género, de la Oficina Regional de la Federación Internacional de Planificación de la Familia, Región del Hemisferio Occidental.

El problema de la violencia contra las mujeres es de tal complejidad que su solución requiere políticas y acciones coordinadas estratégica e intersectorialmente, con la participación del Estado y de la sociedad civil.

Los mayores retos planteados se relacionan, en el corto plazo, con la seguridad de las mujeres, con garantizarles justicia y con impedir la impunidad; en mediano y largo plazo, con lograr un cambio cultural y estructural en la sociedad, que permita erradicar las inequidades de género.

Me gustaría citar parte de un poema de Nadia Anjoman, poetiza afgana, que dice así:

“...¿Cómo puedo hablar de miel cuando tengo veneno en los labios? ¡Como el puño de un opresor, me pega la boca! Yo y el rincón de cautiverio y la tristeza de decepción. Puede que lleve mucho tiempo callada, pero no se me ha olvidado cómo recitar un poema. . . jGloria al día que yo rompa la jaula, Me libere la cabeza del desprecio y cante embriagada!"

No obstante, el "puño del opresor" era más mortífero de lo que tal vez ella hubiera imaginado, pues provenía de los confines del hogar donde vivía. El puño del opresor que la asesinó era la encarnación de todas las fuerzas que se benefician de la opresión de la mujer. Para que Nadia y las demás Nadias puedan escapar de la jaula y cantar con hermosura sus poemas, hay que luchar contra los opresores $\mathrm{y}$ contra los elementos que fortalecen y apoyan a los opresores inmediatos.

María Luisa Ávila-Agüero

Ministra de Salud

\section{Referencias}

1. McPhail BA, Busch NB, Kulkarni S, Rice G. An integrative feminist model: the evolving feminist perspective on intimate partner violence. Violence Against Women. 2007;13:817-41

2. Halim Chowdhury E. Negotiating State and NGO Politics in Bangladesh: Women Mobilize Against Acid Violence. Violence Against Women. 2007;13:857-73

3. Sagot M. The critical path of women affected by family violence in Latin America: case studies from 10 countries. Violence Against Women. 2005;11:1292-318 .

4. Batres-Méndez G. Del ultraje a la esperanza: Tratamiento de las secuelas del incesto. ILANUD. San José, Costa Rica. 1997

5. Batres-Méndez G. Violencia de género, derechos humanos e intervención policial. ILANUD. San José, Costa Rica. 2002

6. Batres-Méndez G. La salud de las mujeres y el género. Med. leg. Costa Rica. 2001;18:10-19.

7. Dekeseredy WS, Dragiewicz M. Understanding the Complexities of Feminist Perspectives on Woman Abuse: A Commentary on Donald G. Dutton's Rethinking Domestic Violence. Violence Against Women. 2007; $13: 874-84$ 